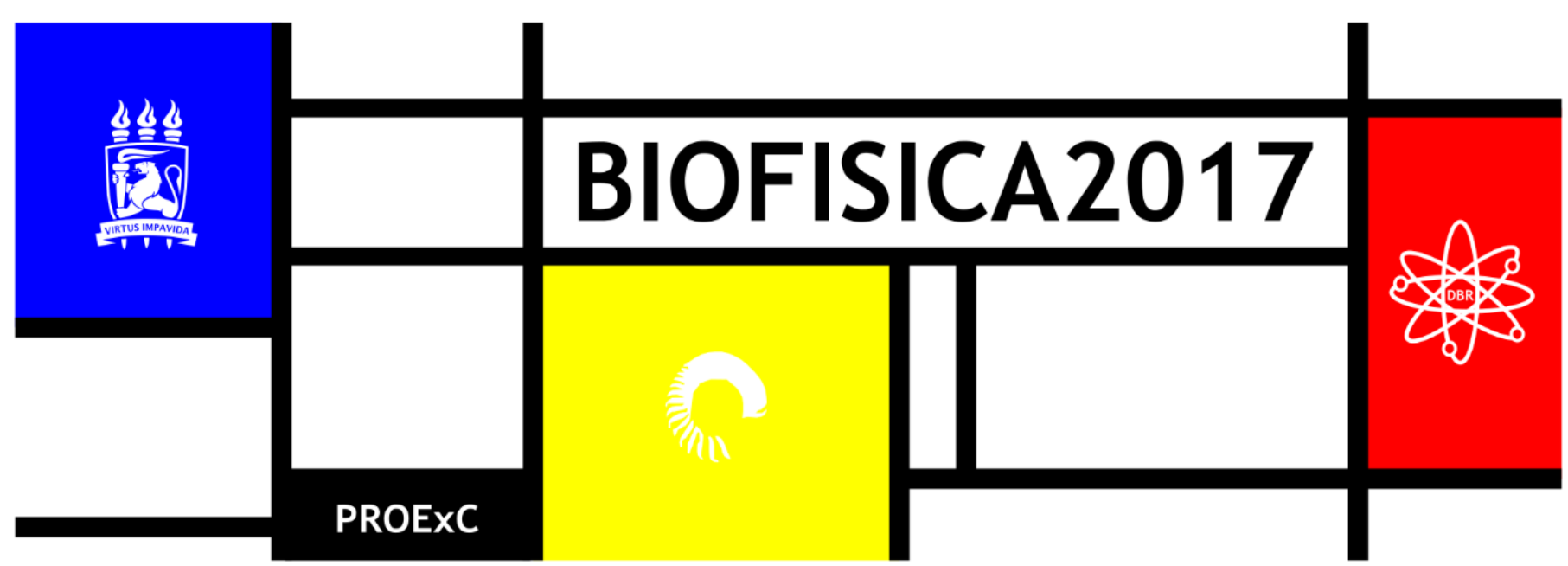

\title{
ENSAIO CITOTÓXICO DE MARISCO Anomalocardia flexuosa (Linnaeus, 1767) NA RESERVA EXTRATIVISTA DE ACAÚ-GOIANA/PB-PE - BRASIL
}

\author{
Anne Maely Maria de Sales Ferreira ${ }^{1 *}$; Marcelo Lucena Lima ${ }^{1}$; Daniel F. P. Junior ${ }^{1}$; Kenia Valenca Correia²; Gilberto \\ G. G. Rodrigues ${ }^{3}$; Sonia Pereira Leite ${ }^{1}$
}

${ }^{1}$ Laboratório de Cultura de Células, Dept ${ }^{\circ}$ de Histologia e Embriologia, UFPE, Brasil; '2Laboratório de Etnoecologia e Educação Ambiental, UFPE, Brasil; ' 'Laboratório de Avaliação, Recuperação e Restauração de Ecossistemas Aquáticos, Dept ${ }^{\circ}$ de Zoologia, UFPE, Brasil.

*annemaely@hotmail.com

\section{INTRODUÇÃO}

A gradativa destruição do meio ambiente causada pela poluição dos estuários e mangues associados, pela sobre exploração de recursos pesqueiros, pelo aterro de manguezais, dentre outros impactos, tem levado a redução de diversos produtos marinhos e estuarinos (Vieira \& Lima, 2003). Estes processos destrutivos têm se concentrado principalmente nas áreas mais utilizadas pela pesca artesanal, como a plataforma continental e águas costeiras rasas de manguezais e estuários, incidindo no atendimento às necessidades proteicas alimentares e econômicas dos pescadores e pescadoras artesanais, que retiram desses ecossistemas, parte de sua subsistência.

As comunidades inseridas nos limites da Reserva Extrativista AcaúGoiana/PB-PE (Resex Acaú-Goiana), localizada na área litorânea interestadual entre os municípios de Pitimbú e Caaporã -Estado da Paraíba e Goiana - Estado de Pernambuco, com aproximadamente de 6.678 hectares, (BRASIL, 2007), dentre as quais ressalta-se a das marisqueiras, possuem uma história de luta contra processos destrutivos dos ecossistemas, da biodiversidade e das atividades tradicionalmente desenvolvidas na área. A própria criação da Reserva foi o resultado de tempos de lutas destas comunidades contra empresários, tentativas de devastação do manguezal local e influências externas negativas contra o meio ambiente.

De acordo com Nishida (2000), para as comunidades que vivem próximas aos manguezais, os moluscos bivalves representam um dos grupos de maior relevância econômica. Nessas áreas, a coleta desses animais pode representar a principal fonte de renda das famílias envolvidas ou complemento de outras atividades extrativistas.

Assim, as marisqueiras de Acaú-Goiana/PB-PE constituem um grupo que garante de forma significativa parte do sustento de suas famílias, além de serem as responsáveis pelo provimento de grande parcela dos recursos pesqueiros, os quais são comercializados nas feiras e mercados e consumidos pela população, veranistas e turistas da região configurando-se em expressivo poder econômico local.
Dentre as espécies de frutos do mar comercializados na região, destaca-se por sua abundância como alvo principal o molusco bivalve da espécie Anomalocardia flexuosa (Linnaeus, 1767), pertencente à família Veneridae com doze subfamílias, aproximadamente cinquenta gêneros e cerca de 500 espécies. As espécies possuem grande capacidade de adaptação a diferentes meios, tais como praias arenosas, areno-lodosas, manguezais e fundos arenosos em ambientes coralíneos. São formadas de conchas sólidas em formato trigonal (RODRIGUES, 2010).

A. flexuosa, conhecido popularmente como marisco chumbinho, macunim, marisco-pedra entre outros nomes, dependendo da região de sua ocorrência. É encontrado do Caribe ao sul do Brasil, sobrevive a uma profundidade de 0,5 a 1,5 m em bancos de areia e possui uma fisiologia alimentar filtradora. Com período de reprodução anual, apresenta-se bastante sensível quanto às variações de temperatura, às chuvas e à salinidade (SILVEIRA, 2013).

Por seu habito filtrador e consequentemente seu potencial bioacumulador de poluentes e contaminantes, os bivalves vem sendo utilizados com sucesso como bioindicadores em bioensaios no monitoramento dos impactos causados pela atividade humana sobre os ecossistemas aquáticos (Rainbow \& Phillips 1993; NOAA 1995; Meyer et al.1998).

Ensaios de citotoxicidade têm sido utilizados com a Artemia salina para avaliar o grau de toxicidade de extratos, visto que o seu ciclo de vida relativamente curto favorece estudos neste sentido. 0 ensaio de toxicidade com estas larvas é rápido, de baixo custo, eficiente e necessita de poucas amostras. Por ser um teste simples não necessita de métodos assépticos, utiliza equipamentos simples e possui boa correlação com a atividade tóxica.

Assim o presente estudo em seu escopo procurou investigar a existência ou não de atividade citotóxica nos extratos de $A$. flexuosa coletada na Resex Acaú-Goiana frente à Artemia salina em diferentes concentrações e, a partir destes achados, colaborar para a conscientização da preservação do habitat natural da espécie estudada e, consequentemente melhorar a qualidade dos 
pescados comercializados na região. O objetivo deste trabalho foi avaliar o efeito citotóxico dos extratos aquosos caldo e maceração do A. flexuosa coletados na Resex Acaú-Goiana, frente a A. salina.

\section{MATERIAIS E MÉTODOS}

Coleta e Conservação do Material

Os espécimes de $A$. flexuosa foram coletados no estuário do Rio Goiana, inserido nos limites da Resex Acaú-Goiana, entre os Estados da Paraíba e Pernambuco. As coletas foram realizadas em terreno arenoso no dia 31 de maio de 2016, no período das 15:00 as 17:00 horas, em profundidades de 30 a $50 \mathrm{~cm}$, com o auxílio de ferramentas artesanais fornecidas pela Associação de Marisqueiras de Acaú (AMA). 0 total de mariscos coletados foi de $1,1 \mathrm{~kg}$, o qual foi armazenado em saco de polietileno, devidamente identificado, acondicionado em caixa de isopor e transportado para o Laboratório de Avaliação, Recuperação e Restauração de Ecossistemas Aquáticos (ARRE Água-UFPE), onde os mariscos foram lavados com água corrente, e posteriormente armazenados em geladeira a temperatura de $4-8^{\circ} \mathrm{C}$, até o início dos ensaios.

Obtenção dos extratos

Para a obtenção dos extratos foram utilizados $200 \mathrm{ml}$ de caldo Macerado e $400 \mathrm{ml}$ de caldo aquoso dos espécimes coletados. Os respectivos caldos foram filtrados em papel filtro de porosidade média, distribuídos em cinco tubos falcon, armazenados por três dias em um freezer a uma temperatura de $-20^{\circ} \mathrm{C}$ e submetidos a processo de liofilização no LIKA (Laboratório de Imunopatologia Keizo Assami).

Determinação da toxicidade frente a $A$. salina Leach

Ensaios de letalidade, empregando como bioindicador a Artemia salina $L$. permitem realizar a avaliação da toxicidade envolvendo apenas um parâmetro: vida ou morte, sendo considerado como ensaio preliminar na identificação de compostos bioativos de baixo custo e fácil manuseio (Cavalcante et al. 2000).

Nesta perspectiva, para a obtenção de larvas de A. salina, cistos deste material biológico foram adquiridos pelo Laboratório Cancerologia Experimental, localizado no biotério do Departamento de Antibióticos da UFPE e induzidos à eclosão por imersão em água do mar ( $\mathrm{pH} 7)$ e temperatura ambiente, e postos em recipiente iluminado com luz artificial $(60 \mathrm{~W})$, por um período correspondente a 24 horas. Decorridas 24 horas, as larvas eclodidas foram avaliadas com base na motricidade e desta forma foi possível utilizar nos ensaios de toxicidade uma população homogênea, com relação ao seu desenvolvimento, a qual foi transferida com o auxílio de uma pipeta de vidro de $5 \mathrm{ml}$ para um béquer de $300 \mathrm{ml}$. Posteriormente os espécimes foram coletados com auxílio de uma Pipeta Pasteur plástica de $3 \mathrm{ml}$, transferidos para uma Placa Petri de onde foram separados em 19 grupos amostrais de 10 indivíduos e transferidos respectivamente para 19 tubos de ensaio contendo concentrações $12,5 \mu \mathrm{g} / \mathrm{ml}, 25,0 \mu \mathrm{g} / \mathrm{ml}$ e $50,0 \mu \mathrm{g} / \mathrm{ml}$ de cada extrato, observando-se o seguinte protocolo: 1 grupo controle onde utilizamos apenas água marinha, o qual foi usado não apenas para comparação com os grupos testes, mas também para se ter certeza de que ocorrendo mortalidade de náuplios de $A$. salina, a mesma seria resultante da toxicidade aos compostos e não devido à falta de alimentação (Carballo et al., 2002) e 2 grupos testes, estes realizados em triplicata para cada concentração de cada composto. Além disso, cada extrato foi testado três vezes por concentração do composto (Vanhaecke et al., 1981; Meyer et al. 1982).

Após $24 \mathrm{~h}$ e $48 \mathrm{~h}$ de exposição os grupos testes foram observados a olho nu, com o intuito de avaliar quantitativamente a viabilidade dos náuplios em relação ao grau de letalidade dos extratos e comparar com o grupo controle.

\section{RESULTADOS E DISCUSSÃO}

Embora que tenha-se observado $100 \%$ da sobrevivência das amostras, conforme dados apresentados nas tabelas 1, 2 e 3, não significa dizer que os testes foram totalmente conclusivos quanto à toxicidade, visto que não foram realizados testes prolongados ou crônicos os quais pudessem avaliar efeitos fisiológicos com comprometimento maior de órgãos ou do sistema reprodutor. Os parâmetros analisados nos ensaios apenas contemplam o estudo da toxicidade aguda. Entretanto, apenas as análises químicas por si só não oferecem parâmetros suficientes para a avaliação dos riscos de contaminação, pois não oferecem parâmetros que determinem a fração de contaminantes dos animais vivos nem o seu efeito potencial após misturados (PIMENTA, 2011). Não foram realizados testes de toxicicidade crônica que pudessem avaliar problemas causados a longo prazo para avaliação dos efeitos cumulativos, fazendo-se necessário estudos mais aprofundados a este respeito.

A Ecotoxicologia aquática é uma ciência auxilia a elucidação dos mecanismos fisiológicos dos organismos vivos expostos a produtos químicos decorrentes da poluição ambiental e como estes animais respondem a estes efeitos. Os ensaios de toxicidade aguda são ferramentas que nos auxiliam na avaliação e monitoramento de forma rápida e severa das condições de vida em ambientes impactados frente aos organismos analisados. 0 objetivo do teste é observar o efeito de letalidade e/ou alterações quanto à mobilidade dos indivíduos causados pelas diferentes concentrações a que os mesmos são expostos. Estes parâmetros são determinados através da Conecentração Letal Média (CL50), que é a concentração que causa mortalidade de $50 \%$ da população estudada após um determinado tempo de exposição ao agente tóxico (MAGALHÃES \& FERRÃO FILHO, 2008).

Os ensaios de letalidade com o microcrustáceo $A$. salina têm larga aplicação para verificação da toxicidade de compostos bioativos presente em extratos vegetais, mas também vem sendo empregados em ensaios de toxicidade de alguns extratos frente a organismos marinhos de pequeno porte, como peixes e pequenos crustáceos (SILVA, 2015).

Diante dos resultados obtidos após o teste de letalidade com $A$. salina, verificamos que todas as amostras analisadas não apresentaram potencial tóxico, pois ao final do estudo todos os indivíduos permaneceram vivos e sem comprometimento motor aparente.

Ensaios de toxicidade frente à $A$. salina são usualmente utilizados para avaliação de extratos aquosos vegetais para determinação da CL50. Este bioensaio é largamente utilizado devido ao baixo custo, rapidez na execução e boa reprodução quanto à interpretação dos resultados reproduzindo com fidedignidade algumas atividades biológicas como a atividade antitumoral, antibacteriana, antifúngica e contra o Trypanossoma cruzi (SILVA, 2013). Até então não foram encontrados na literatura ensaios aplicados a espécies bivalves. Entretanto, como se trata da avaliação da toxicidade este método é o mais aplicado para avaliação da citotoxicidade de extratos aquosos (MEYER, 1982). Ao final do experimento observamos que em todas as amostras analisadas houve sobrevida de $100 \%$ do microcrustáceo $A$. salina, tanto nas amostras de controles negativo e positivo quanto nas expostas a diferentes concentrações dos extratos, durante 24 horas, conforme observado nas tabelas 1 e 2 . As análises em $24 \mathrm{~h}$ e $48 \mathrm{~h}$ demonstraram que os organismos apresentaram boa motricidade e tamanho normal para o seu estágio de desenvolvimento, indicando que não houve interferência quanto à citotoxicidade nos estágios de crescimento. Passadas $72 \mathrm{~h}$ do início do experimento observou-se que a espécie continuou apresentando sinais de motricidade.

Os mariscos, comumente consumidos pela população costeira, destacam-se não apenas pelo potencial econômico para subsistência daquela população, mas também pelo seu elevado valor nutricional como rica fonte de proteínas e sais minerais (zinco, ferro e cobre) (PEDROSA, 2001). Entretanto, apesar dos resultados apontarem para a ausência de citotoxicidade, estudos anteriores comprovaram que a presença de metais leves e pesados $(\mathrm{Cu}, \mathrm{Fe}, \mathrm{Hg}, \mathrm{Mn}$ e $\mathrm{Zn}$ ) em moluscos bivalves os quais são de grande relevância para a avaliação da poluição ambiental do local onde vivem e por este motivo podem também levar a um efeito cumulativo destes metais (CAVALCANTI, 2003). Estes moluscos são 
bastante utilizados como bioindicadores presença de contaminantes e metais traço (Chagas-Spinelli, 2006). Estudos realizados através do teste de letalidade permitem apenas a avaliação da citotoxicidade, mas não para danos relacionados ao efeito cumulativo.

Tabela 1 - Viabilidade e sobrevida da $A$. salina frente ao extrato aquoso por maceração

\begin{tabular}{|l|l|l|}
\hline & $\begin{array}{l}\text { Viabilidade } \\
\text { sobrevida (\%) }\end{array}$ & \\
\hline $\begin{array}{l}\text { Concentrações } \\
\text { (microlitros/mL) }\end{array}$ & Grupo controle & $\begin{array}{l}\text { Grupo } \\
\text { (Extrato } \\
\text { Maceração) }\end{array}$ \\
\hline 12,5 & 100 & 100 \\
\hline 25,0 & 100 & 100 \\
\hline 50,0 & 100 & 100 \\
\hline 100 & 100 & 100 \\
\hline
\end{tabular}

Tabela 2 - Viabilidade e sobrevida da A. salina frente ao extrato aquoso caldo.

\begin{tabular}{|l|l|l|}
\hline & $\begin{array}{l}\text { Viabilidade } \\
\text { sobrevida (\%) }\end{array}$ & \\
\hline $\begin{array}{l}\text { Concentrações } \\
\text { (microlitros/mL) }\end{array}$ & Grupo controle & $\begin{array}{l}\text { Grupo teste } \\
\text { (Extrato Aquoso } \\
\text { Caldo) }\end{array}$ \\
\hline 12,5 & 100 & 100 \\
\hline 25,0 & 100 & 100 \\
\hline 50,0 & 100 & 100 \\
\hline 100 & 100 & 100 \\
\hline
\end{tabular}

Tabela 3 - Estudo comparativo entre os extratos caldo e macerado

\begin{tabular}{|l|l|l|l|l|}
\hline Extratos & & $\begin{array}{l}\text { Concentrações } \\
(\mu \mathrm{g} / \mathrm{ml})\end{array}$ & $\begin{array}{l}\text { Viabilidade } \\
(\%)\end{array}$ \\
\hline & 12,5 & 25,0 & 50,0 & 100 \\
\hline Caldo & 10 & 10 & 10 & 100 \\
\hline Macerado & 10 & 10 & 10 & 100 \\
\hline
\end{tabular}

A ausência de citotoxicidade dos extratos testados frente à A. salina é um indicador de que os organismos em estudo podem ser bem tolerados frente aos extratos analisados (STEFANELLO, 2006).

\section{CONCLUSÃO}

Os resultados observados foram conclusivos para avaliar quantitativamente o grau de citotoxicidade dos extratos aquosos caldo e maceração, e perceptíveis quanto ao poder nutricional afirmados pelas marisqueiras, visto os microcrustáceos apresentavam uma massa um pouco maior em relação ao grupo controle, conforme uma percepção a olho nu. Portanto pôde-se concluir que devido à ausência total de atividades citotóxicas frente Artemia salina o consumo dos mariscos da espécie Anomalocardia flexuosa (Linnaeus, 1767), popularmente conhecidos como marisco-pedra e encontrados na região de Acaú não são tóxicos, portanto se consumidos de forma adequada não oferecem riscos à saúde humana.

\section{REFERÊNCIAS}

BRASIL, Presidência da República - Casa Civil, Decreto 26 de setembro de 2007. Cria a Reserva Extrativista Acaú-Goiana, nos Municípios de Pitimbú e Caaporã, no Estado da Paraíba, e Goiana, no Estado de Pernambuco, Brasília - DF

CARBALLO JL, HÉRNANDEZ-INDA Z. L., PÈREZ P, GARCÍAGRAVELALOS MD. A comparison between two brine shrimp assays to detect in vitro citotoxicity in marine natural products. BMC Biotechnolog 2:17, 2002

CAVALCANTE, MF et al. Sintese de 1,3,5-triazinas substituidas e avaliacao da toxicidade frente a Artemia salina Leach. Quím. Nova , Sao Paulo. 2000;23(1):20-2.
CAVALCANTI 2003. Monitoramento da contaminação por elementos traço em ostras comercializadas em Recife, Pernambuco, Brasil, Cad. Saúde Pública, Rio de Janeiro, 19(5):1545-1551, set-out, 2003 CHAGAS-SPINELLI A. C. O., COSTA, M. F., LIMA, E.S., Avaliação de métodos de preservação de tecidos moles de moluscos bivalves para análise geoquímica e uso como bioindicadores de contaminação ambiental: caso do estuário de Barra de Jangadas, Nordeste do Brasil. Estudos Geológicos v. 16 (2), 2006

FADIGAS A. B. M, GARCIA L. G. Uma análise do processo participativo para a conservação do ambiente na criação da Reserva Extrativista Acaú-Goiana, Sociedade \& Natureza, Uberlândia, 22(3) , 561-576, dez. 2010.

MAGALHÃES D. P. \& FERRÃO FILHO, A. S. F. A ecotoxicologia como ferramenta de biomonitoramento de ecossistemas aquáticoa, Oecol. Bras., 12 (3) 355-381, 2008.

MEYER B.N., Brine Shrimp: A Convenient General Bioassay for Active Plant Constituents, Planta Medica, Vol. 45, pp.33-34, 1982. PEDROSA L. F. C., COZZOLINO, S. M. F.. COMPOSIÇÃO CENTESIMAL E DE MINERAIS DE MARISCOS CRUS E COZIDOS DA CIDADE DE NATAL/RN, Ciênc. Tecnol. Aliment., Campinas, 21(2): 154-157, maio-ago. 2001.

PIMENTEL M. F.,F. C. G. Silva Júnior, S. T. Santaella \& L. V. C. Lotufo, O Uso de Artemia sp. como Organismo-Teste para Avaliação da Toxicidade das Águas Residuárias do Beneficiamento da Castanha de Caju Antes e Após Tratamento em Reator Biológico Experimental, J. Braz. Soc. Ecotoxicol., v. 6, n. 1, 2011 RODRIGUES, AML, AZEVEDO CM, SILVA GGH. Aspectos da biologia e ecologia do molusco bivalve Anomalocardia brasiliana (Gmelin, 1791) (Bivalvia, Veneridae)R. bras. Bioci., Porto Alegre, v. 8, n. 4, p. 377-383, out./dez. 2010.

SILVEIRA, P. C. B., MESQUITA B.; MELO L.; FILHO I. O.. Estuário, paisagem- fluxo de pescadores artesanais. Iluminuras, Porto Alegre, v. 14, n. 34, p. 304-323, ago./dez. 2013

SILVA, CB.da...ESTUDO DA CITOTOXICIDADE DE Indigofera suffruticosa MILL SOBRE Artemia salina. Silva, C.B. da; Santos, B.S. dos; Santos, I.P.; Lima, V.L.M. Resumos Expandidos do I CONICBIO / II CONABIO / VI SIMCBIO (v.2) Universidade Católica de Pernambuco - Recife - PE - Brasil - 11 a 14 de novembro de 2013 STEFANELLO MEA, Salvador MJ, Ito MY, Macari PAT. Avaliação da atividade antimicrobiana e citotóxica de extratos de Gochnatia polymorpha ssp floccosa. Rev Bras Farmacogn. 2006;16(4):525-30.

SILVA E. M. F., Estudo in vitro do potencial citotóxico da Annona muricata L. Egidi Mayara Firmino Silva,*; Renata Barreto de Castro Nascimento; Francisco Stefânio Barreto; Manoel Odorico de Moraes Filho; Samara de Almeida Souza Griz3; Aldenir Feitosa dos Santos; Kristiana Cerqueira Mousinho, Rev Ciênc Farm Básica Apl., 2015;36(2):277-283 ISSN 1808-4532

VANHAECKE P, PERSOONE G, CLAUS C, SORGELOOS P. Proposal for a short-term toxicity test with Artemi nauplii. Ecotoxicol Enviroment Safety. 1981;5:382-7. 